\title{
Video feedback in English for Academic Purposes: building connections with international students while learning online
}

Jade Kimberley

University of Nottingham International College

\section{Chiara Matthews}

University of Nottingham International College

\section{Vanessa Smith}

University of Nottingham International College

\section{Jo Leech}

University of Nottingham International College

Key words: feedback; video feedback; screencast feedback; higher education; connection; digital literacy; Covid-19.

\section{The challenge}

The transition to online teaching and learning in higher education called upon practitioners to investigate new ways to support and connect with their students. It also prompted a wave of investment in training on learning technologies, inspiring experimentation when communicating asynchronously with learners. The loss of face-to-face classroom interaction elicited concerns over levels of engagement and motivation, as it became clear that students at our pathways college would complete their programme of study online and would not return to a physical classroom. A clear link had been established demonstrating the significant impact of attendance and engagement on meeting learning outcomes, so measures were required to ensure student success and maintain the levels of support offered in college. Additionally, the increased working demands of transitioning online meant that any measures taken would need to avoid extra tasks on top of an already heavier workload for teaching staff.

All teaching was taking place synchronously, and so it was felt that stronger connections with students should be forged asynchronously, for example, when giving feedback on written work. The aims were to increase engagement, provide support and encouragement 
via verbal and non-verbal cues not present in text feedback, and to complete the feedback process in a more timely and efficient manner, in turn developing tutors' digital literacy.

\section{The response}

A small group of tutors decided to experiment with providing video feedback on English for Academic Purposes (EAP) and Project formative assessments. This was in the form of screencasts, both with and without a webcam window in which the tutor was visible. Tutors provided comments as they scrolled through the assessment, highlighting areas using the cursor.

Studies have reported that students respond positively to video feedback (McCarthy, 2015; Espasa et al., 2019; Bahula and Kay, 2020; Cunningham and Link, 2021). This is partly attributed to the conversational cues and paralinguistic features absent in text feedback (Ajjawi and Boud, 2017; Ryan, 2020), but which through video present a means of social interaction (Mahoney et al., 2019; Lowenthal et al., 2020; Ryan, 2020). Students also consider this mode of delivery more personalised (McCarthy, 2015; Anson et al., 2016; Bahula and Kay, 2020), and tutors concurred with this. While video feedback is, in essence monologic, learners consider it conversational (Borup et al., 2015; Anson et al., 2016), although there have been calls for more efforts to be made to produce feedback that opens up a dialogue (Mahoney et al., 2019). As students would have an opportunity for an online tutorial after video feedback was released, it was hoped that it would start an ongoing conversation as their projects developed.

There is also evidence to suggest that this mode of feedback can help to strengthen the relationship between tutor and student (Anson et al., 2016; Espasa et al., 2019; Bahula and Kay, 2020; Ryan, 2020), and form connections, especially important during the pandemic (Lowenthal et al., 2020; Cunningham and Link, 2021). This was a common aim among tutors, who wanted to mimic the one-to-one tutorials students would usually have in college and offer a similar experience to students starting their course later in the term. Video feedback was also seen as an opportunity to emphasise important aspects of the students' work and draw attention to areas for development. 
Some students initially reported that they liked the video format, while others said they would prefer it together with text that they could refer back to more easily. When one tutor asked if her class would like to receive video feedback on their next assessment, they indicated a preference for feedback in an email, as they felt this was clearer. Given the effort made to foster a deeper connection and provide better one-to-one support, this surprised tutors and prompted reflection and curiosity.

\section{Recommendations}

There were several learning points from this experiment. Studies have suggested that drawbacks to video feedback include downloading large files and not having clear instructions on how to access recordings (McCarthy, 2015; Bahula and Kay, 2020; Davies et al., 2020). The linear nature of video feedback can also lead to time-consuming reviewing to locate certain comments (Bahula and Kay, 2020), although a screencast which scrolls through a written assessment could help to avoid this. A significant conclusion from this process, therefore, was the need for clear guidance on how to retrieve feedback, along with using software which facilitated ease of access (including LMS or VLE integration, where possible).

Another notable reflection is that, while one-to-one online support is invaluable in the current educational climate, there may be no realistic substitute for face-to-face delivery and tutorial support in person. It was felt that video feedback was the closest tutors could get to face-to-face interaction, but the amount of time students spend in online lessons can lead to over-exposure and fatigue (Lowenthal et al., 2020). Although video recordings are asynchronous and accessed when convenient, they essentially contribute to more screen time, which may be undesirable.

While teaching staff have taken the pivot to online learning as an opportunity to develop their skills involving learning technology, levels of digital literacy varied at the start of the pandemic (Liu et al., 2020), and this continues to be the case. It is essential that if video feedback is adopted, all staff are given the appropriate support and training to develop competence and confidence in this area. One goal of our experiment was to save time 
compared with writing comments (Cunningham and Link, 2021), but evidence suggests creating videos can be more time-consuming (McCarthy, 2015; Davies et al., 2020), and it is likely that digital literacy plays a role in this.

Research specifically concerning video feedback is less common than that on text feedback, but rarer still are feedback studies involving learners who are not studying in their first language (McCarthy, 2015; Bakla, 2020). Bakla (2020) notes that international students are reluctant to engage with video feedback because it is unfamiliar to them, which suggests a need to coach students on how to access, interpret and engage with their feedback to help them adjust to receiving it in a different format. Students' listening skills in the target language should also be considered, as lower level learners may struggle with listening and watching simultaneously. Consequently, more substantive research is called for, in which international student feedback is gathered to understand perceptions of video feedback and the reasons behind them. Using different feedback modalities is feasible across the higher education sector, but care must be taken to support educators in developing competencies, providing clear instructions for access, listening to recipients' feedback and making adaptations so that feedback is meaningful and encouraging, and motivates learners to improve their work.

\section{References}

Ajjawi, R. and Boud, D. (2017) 'Researching feedback dialogue: an interactional analysis approach', Assessment \& Evaluation in Higher Education, 42(2), pp.252-265.

Available at: https://doi.org/10.1080/02602938.2015.1102863 (Accessed: 22 June 2021).

Anson, C., Dannels, D., Laboy, J. and Carneiro, L. (2016) 'Students' perceptions of oral screencast responses to their writing: exploring digitally mediated identities', Journal of Business and Technical Communication, 30(3), pp.378-411. Available at: https://doi.org/10.1177/1050651916636424 (Accessed: 22 June 2021). 
Bahula, T. and Kay, R. (2020) 'Exploring student perceptions of video feedback: a review of the literature', 13th Annual International Conference of Education, Research and Innovation (ICERI2020) Proceedings, pp. 6535-6544. Available at: http://dx.doi.org/10.21125/iceri.2020.1398 (Accessed: 22 June 2021).

Bakla, A. (2020) 'A mixed-methods study of feedback modes in EFL writing', Language Learning and Technology, 24(1), pp.107-128. Available at: https://doi.org/10125/44712 (Accessed: 22 June 2021).

Borup, J., West, R. and Thomas, R. (2015) 'The impact of text versus video communication on instructor feedback in blended courses', Educational Technology Research and Development, 63, pp.161-184. Available at: https://doi.org/10.1007/s11423-015-9367-8 (Accessed: 22 June 2021).

Cunningham, K. and Link, S. (2021) 'Video and text feedback on ESL writing: understanding attitudes and negotiating relationships', Journal of Second Language Writing, 52, 100797. Available at: https://doi.org/10.1016/j.jslw.2021.100797 (Accessed: 22 June 2021).

Davies, J., Davies, L., Conlon, B., Emerson, J. Hainsworth, H. and McDonough, H. (2020) 'Responding to COVID-19 in EAP contexts: a comparison of courses at four Sinoforeign universities', International Journal of TESOL Studies, 2(2), pp.32-51. Available at: https://doi.org/10.46451/ijts.2020.09.04 (Accessed 23 June 2021).

Espasa, A., Mayordomo, R., Guasch, T. and Martinez-Melo, M. (2019) 'Does the type of feedback channel used in online learning environments matter? Students' perceptions and impact on learning', Active Learning in Higher Education, pp.1-15. Available at: https://doi.org/10.1177/1469787419891307 (Accessed: 22 June 2021).

Liu, Q., Geertshuis, S. and Grainger, R. (2020) 'Understanding academics' adoption of learning technologies: a systematic review', Computers and Education, 151, 103857. Available at: https://doi.org/10.1016/j.compedu.2020.103857 (Accessed: 22 June 2021). 
Lowenthal, P., Borup, J., West, R. and Archambault, L. (2020) 'Thinking beyond Zoom: using asynchronous video to maintain connection and engagement during the COVID-19 pandemic', Journal of Technology and Teacher Education, 28(2), pp.383-391. Available at: https://www.learntechlib.org/primary/p/216192/ (Accessed 1 May 2021).

Mahoney, P., Macfarlane, S. and Ajjawi, R. (2019) 'A qualitative synthesis of video feedback in higher education', Teaching in Higher Education, 24(2), pp.157-179. Available at: https://doi.org/10.1080/13562517.2018.1471457 (Accessed: 22 June 2021).

McCarthy, J. (2015) 'Evaluating written, audio and video feedback in higher education summative assessment tasks', Issues in Educational Research, 5(2), pp.153-169. Available at: http://www.iier.org.au/iier25/mccarthy.pdf (Accessed 2 May 2021).

Ryan, T. (2020) 'Designing video feedback to support the socioemotional aspects of online learning', Educational Technology Research and Development, 69, pp.137-140. Available at: https://doi.org/10.1007/s11423-020-09918-7 (Accessed: 22 June 2021).

\section{Author details}

Jade Kimberley is an Academic Leader at the University of Nottingham International College. She is a Senior Fellow of Advance HE and a Senior Certified Member of the Association for Learning Technology. Her research interests include digital literacies, continuous professional development and innovations in technology enhanced learning.

Chiara (Kiki) Matthews is an Academic Manager at the University of Nottingham International College, where she leads on an Extended English and Skills programme. She is interested in promoting student success by developing language skills and knowledge of academic conventions. 
Vanessa Smith is an English Language and Study Skills Tutor, and EAP Coordinator at the University of Nottingham International College. She is interested in improving student engagement in online learning spaces.

Jo Leech is an English Language, Research \& Study Skills tutor at the University of Nottingham International College, with a specific interest in learner motivation and engagement. 